\title{
Factors related to autonomy among Lebanese women: a web-based cross-sectional study
}

\author{
Sandrella Bou Malhab 1,2,9, Hala Sacre ${ }^{1}$, Diana Malaeb ${ }^{1,2}$, Nathalie Lahoud ${ }^{1,3,4}$, Dalia Khachman ${ }^{5}$, Joelle Azzi ${ }^{3}$, \\ Chadia Haddad ${ }^{1,6,7^{*}+}$ and Pascale Salameh ${ }^{1,4,8+}$
}

\begin{abstract}
Background: Autonomy involves making independent decisions and creating lasting and equitable power relationships within families. Many factors, dependent on both the woman and her partner, can influence self-dependence, and subsequent decision-making, exerting a protective or triggering effect on its development. Therefore, the primary objective of the study was to assess autonomy in a sample of Lebanese women. The secondary objective was to evaluate the association between socioeconomic status, psychological factors, and autonomy.

Methods: A web based cross-sectional online study was conducted between June 8 and August 1, 2020. The questionnaire developed on Google Forms was distributed through social media and WhatsApp groups, using the snowball technique. The Women's Autonomy Index (WAl) was created using three items adapted from a previous study. In addition, the Composite Abuse Scale Revised-Short Form (CASR-SF) was used to assess three domains of abuse: physical, sexual, and psychological. The Perceived stress scale short version to measure stress perception, the Lebanese Anxiety Scale to measure anxiety and the Patient Health Questionnaire (PHQ-9) to assess depression. The Statistical Package for the Social Sciences (SPSS) software version 25 was used for data analysis. Linear regressions were performed, taking the Women's Autonomy Index as the dependent variable.
\end{abstract}

Results: The sample consisted of 369 Lebanese women. University education level (beta $=1.263$ ), alcohol consumption (beta $=0.586$ ), intermediate income level (beta $=0.702)$, high income (beta $=0.911)$, employment (beta $=0.559)$, and older age (beta $=0.033$ ) were significantly associated with higher WAl. Living in South Lebanon (beta $=-0.668$ ) and being Druze (beta $=-323$ ) were associated with lower WAl. Significantly higher mean scores of anxiety and perceived stress were found among women with low autonomy.

Conclusion: In Lebanon, the autonomy of women depends on several personal and partner-related characteristics (education, socioeconomic status, age), in addition to the cultural (geographic and religious) environment. Furthermore, low autonomy is associated with higher perceived stress and anxiety and probable depression and domestic abuse.

Keywords: Women, Independence, Autonomy, Anxiety, Stress, Depression

*Correspondence: Chadia_9@hotmail.com

${ }^{\dagger}$ Chadia Haddad and Pascale Salameh last co-authors

${ }^{6}$ Research Department, Psychiatric Hospital of the Cross, P.O. Box 60096,

JalEddib, Lebanon

Full list of author information is available at the end of the article

\section{Introduction}

Autonomy or self-dependence is the ability to make decisions for oneself, to control one's own body, and to determine how to use resources without needing to consult or seek permission from another person [1]. In women, it 
can be viewed as the control over their own lives, materials, access to knowledge and information, and having equal contribution and opinions with their husbands or partners on matters affecting them and their families [13]. Autonomy involves making independent decisions, overcoming the constraints of physical mobility, and creating lasting and equitable power relationships within families [4].

The few studies that assessed this topic in developing countries suggest a close link between autonomy and the sociodemographic characteristics of women and the social environment in which they live. Many factors, dependent on both the woman and her partner, can influence self-dependence, and subsequent decision-making, exerting a protective or triggering effect on its development [5]. Indeed, education [6], employment and high household income [1,7], older age [8], residing in urban areas [9], living with an educated and employed partner $[1,10]$, and having good marital relationships [11] are all predictors of greater autonomy in women, increasing their self-confidence, assertiveness, and decision-making. Oppositely, poverty [2] and religion [8] exacerbate their dependence and decrease their self-esteem. Furthermore, a few studies showed that women's autonomy, including decision-making, is associated with psychological factors such as anxiety, stress, and depression [12-14].

In Lebanon, despite many vested benefits and rights, Lebanese women face discrimination on many levels, rooted in law and regulations, sectarian considerations, religious socio-cultural values differing according to religions, decision-making structures, public policies, development strategies, ongoing conflicts, security issues, and a rise in social conservatism. The absence of women from decision-making is mainly due to the patriarchal character of the society governed by customary and religious beliefs rather than codified law [15]. Various sects and religious communities, traditionally dominated by male members of the leading families, undermines the possibility of involvement of women in the decision process [15].

All these factors enhance the vulnerability of women and make gender equality in Lebanon an elusive goal. Furthermore, the economic system in Lebanon relies on minimal taxation and a commitment to the free market, favoring the private sector by giving it strong dominance over vital public services, including education, thus resulting in a significant gap in educational outcomes between public and private education, which reduces equal opportunities for children [15].

Our research hypothesis was that higher education, higher monthly income, Christian religion, being employed, and low violence are associated with higher autonomy, which, in turn, is associated with lower stress, anxiety, and depression. Therefore, the primary objective of the study was to assess autonomy in a sample of Lebanese women. The secondary objective was to evaluate the association between socioeconomic status, psychological factors, and autonomy.

\section{Methods}

\section{Study design and sampling}

A web based cross-sectional study conducted online between June 8 and August 1, 2020, using the snowball technique from all Lebanese regions (Beirut, Mount Lebanon, North, South, and Beqaa). Inclusion criteria were married women, aged 18 to 51, living with their partner, and with internet access. Exclusion criteria were single, widowed, or divorced women and those with fertility problems. The eligibility criteria were available in the consent section at the beginning of the online survey that required $40 \mathrm{~min}$ to complete. The questionnaire was pilot-tested on ten women to check the clarity, and the data included in the final database. Participation was anonymous and voluntary, and participants received no compensation for joining the study.

\section{Procedure}

The online survey consisted of closed-ended questions in English and Arabic. The questionnaire was developed on Google Forms, and the link was distributed through social media and WhatsApp groups.

Approval was obtained from the ethics committee of The Psychiatric Hospital of the Cross (HPC-018-2020). All procedures were performed in accordance with relevant guidelines. Also, the procedure of this article followed the Strobe statement checklist (Additional file 1).

\section{Sample size calculation}

The sample size was calculated through two methods using the G-power software.

In the first method, the calculation considered the effect size between two means (abused and non-abused women) of the Women's Autonomy Index. Based on an effect size of 0.56 , an alpha error of $5 \%$, and a power of $96 \%$, the minimum sample required was 140 participants.

In the second method, the calculation was based on the number of predictors to be entered in the multivariable analysis. The minimum sample required was 311 women, based on an effect size $\mathrm{f} 2=2 \%$, an alpha error of $5 \%$, a power of $80 \%$, and taking into consideration 17 factors to be entered in the multivariable analysis.

The authors adopted the second calculation method since it yielded a higher sample size allowing for better analysis. The final sample size comprised of 369 . 
The variables used to perform the calculation are described in the questionnaire section below.

\section{Questionnaire}

The questionnaire included two sections (Additional file 2). The first assessed the sociodemographic features of women and those of their partners as reported by the respondent, such as age, educational level, the region of residence, the number of rooms and the number of people living in the house, religion, working status, monthly income, smoking, alcohol status, duration of confinement, and physical activity. The confinement period corresponds to the sanitary lockdown mandated by the Lebanese government to face the COVID-19 pandemic as of February 2020. The household crowding index was calculated by dividing the number of persons living in the house by the number of rooms, excluding bathrooms and the kitchen [16]. The monthly income was divided into four levels: no income, low $<1000$ USD, intermediate 1000-2000 USD, and high income $>2000$ USD. Fear of poverty was also assessed and rated on a Likert scale from 0 (no fear) to 10 (extreme fear). The physical activity consisted of any sports and fitness workout practiced during confinement to stay fit and healthy; it was assessed using dichotomous questions (Yes/No).

The second part consisted of the following scales:

\section{The Women's Autonomy Index (WAl)}

This index was created using questions adapted from a previous study [17]. It consisted of three questions: (1) Do you have the capacity to open and operate your own bank account?; (2) Do you have the capacity to meet the financial needs of your family?; and (3) What are the places where you can go alone (unaccompanied)? Questions 1 and 2 had three possible answers rated from 0 to 2, while question 3 had four possible answers and a score from 0 to 3 . The total score ranged between 0 and 7 , where a higher score indicates higher woman independence.

\section{The Composite Abuse Scale Revised-Short Form (CASR-SF)}

This 15-item scale is a self-report tool covering three domains of abuse (i.e., physical, sexual, and psychological) and evaluating abuse exposure and frequency [18]. It was developed by Ford-Gilboe et al. among 6278 adult Canadian women and had an internal consistency of 0.942 [18]. Moreover, correlations were moderate between the CASR-SF and the measures of depression, post-traumatic stress disorder, and coercive control [18]. The total score is calculated by summing the 15 responses rated from 0 to 6 , with a higher score indicating a higher intensity/ occurrence of abuse. Three subscales scores were derived from the total score, reflecting physical (4 items), sexual
(2 items), and psychological (6 items) abuse [18]. The scale was dichotomized into non-abused (answering 0 to all questions) and abused (answering at least 1 to any question). Pr. Marilyn Ford-Gilboe, the author of the questionnaire, authorized its use in this study.

\section{Perceived stress scale short version (PSS-4)}

Three versions of the Perceived Stress Scale are available: PSS-14 (14 items), PSS-10 (10 items), and PSS-4 (4 items). The original 14-item instrument was in English; it consisted of seven positive items and seven negative items rated on a 5-point Likert scale [19]. It has demonstrated good reliability, with Cronbach's alpha ranging from 0.75 to 0.91 [20]. The PSS has been translated into several languages and evaluated in various cultures and countries [20]. Chaaya et al. validated the Arabic version of the PSS-10 items in Lebanon among 268 women and found a good validity with an adequate internal consistency of 0.74 [21]. Almadi et al. validated another Arabic version of the PSS-14 in Jordan among 126 participants; the Cronbach's alpha was 0.80 , and the test-retest reliability had an intra-correlation coefficient of 0.90 [22]. In the current study, the 4-item version was used as a brief measure was required to measure the stress perception as a potential confounder. Answers are rated on a scale from 0 (never) to 4 (very often). The total score is calculated by summing the four responses and ranges from 0 to 16 , with higher scores indicating more perceived stress [19].

\section{Lebanese Anxiety Scale (LAS-10)}

This 10-item self-report scale is used to screen for anxiety [23]. It was developed and validated in Lebanon by Hallit et al. among 1332 Lebanese adults and showed a good internal consistency of 0.857 and good sensitivity and specificity $(77.5 \%$ and $70.8 \%$, respectively). The positive predictive value of the LAS- 10 score was $26.9 \%$, and the negative predictive value was $95.2 \%$ [23]. Seven of the items are graded on a 5 -point Likert scale $(0=$ Not present to $4=$ very severe), and the remaining three, on a 4 -point Likert scale $(1=$ almost never to $4=$ almost always) [23]. The total score is calculated by summing all the responses, with higher scores indicating higher anxiety [23].

\section{Patient Health Questionnaire (PHQ-9)}

The PHQ-9 consists of nine questions used to screen for the presence and severity of depression [24]. Its diagnostic validity has been established in two studies involving 3000 patients in eight primary care clinics and 3000 patients in seven obstetrics-gynecology clinics, respectively $[25,26]$. It had a sensitivity of $88 \%$ and a specificity of $88 \%$ for detecting major depressive disorder, in 
addition to adequate reliability and validity and a high internal consistency $[25,26]$. In Lebanon, Sawaya et al. translated and validated the PHQ-9 among 186 Lebanese adult psychiatric patients [27]; the scale showed a high internal consistency (Cronbach's alpha $=0.88$ ) and an adequate factor analysis [27]. Based on a cutoff of 10, it had a sensitivity of $77 \%$ and a specificity of $46 \%$ for detecting depressive symptoms [27]. All items are rated from 0 (not at all) to 3 (nearly every day). The PHQ-9 total score ranges from 0 to 27, with higher scores reflecting a more severe depression.

\section{Statistical analysis}

Statistical Package for the Social Sciences (SPSS) software version 25 (SPSS Inc., Chicago, IL, USA) was used for data analysis. No missing values was detected in the database. Cronbach's alpha values were recorded for the reliability analysis of all scales. In the descriptive analysis, counts and percentages were used for categorical variables and means and standard deviations for continuous measures. The Women's Autonomy Index was normally distributed according to the histogram and the kurtosis and skewness values. Two linear regressions were performed, taking the Women's Autonomy Index as the dependent variable, and included the variables that showed a $p$ value less than 0.05 in the bivariate analysis to minimize confounding. Also, a multivariate General Linear Model was conducted, comparing mental health variables between autonomous and non-autonomous women, after adjusting for sociodemographic characteristics. A value of $p<0.05$ was considered statistically significant.

\section{Results}

\section{Sample description}

Table 1 presents the details of the sociodemographic and other characteristics of the participants. Of the 369 total sample, $72 \%$ answered the Arabic questionnaire, while $28 \%$ preferred the English version. The percentage of women with university education was higher than that of their partners, while employment and income were much higher among men. The majority of participants were from Mount Lebanon and Beirut (76.4\%); the others were from North (11.9\%), South (6.5\%), and Beqaa (5.1\%). The mean duration of confinement was $71.0 \pm 42.8$ days, and the mean fear of poverty was 5.8 .

\section{Description of the scales used}

The mean WAI was $4.32 \pm 1.55$ with a Cronbach's alpha value of 0.328 . The factor analysis of the scale is presented in Additional file 3: Table S1. In the absence of cut-off values for WAI, the median was considered a cut-off point for higher and lower autonomy. The mean total CASR-SF was $1.97 \pm 5.83$ with a Cronbach's alpha value of 0.902 for the full scale. Cronbach's alpha values for the subscales of CASR-SF were 0.791 for the psychological abuse subscale, 0.759 for the physical abuse subscale, and 0.740 for the sexual abuse subscale. The factor analysis of the scale is presented in Additional file 3: Table S2. The mean PSS- 4 was $7.35 \pm 2.62$ with a Cronbach's alpha value of 0.484 , and the mean LAS-10 scale was $14.44 \pm 7.38$ with a Cronbach's alpha value of 0.890 . The mean PHQ-9 was $7.02 \pm 5.44$ with a Cronbach's alpha value of 0.893 .

Moreover, only $7.9 \%$ of women reported being able to meet the financial needs of their family, while $55.0 \%$ can go alone to any place, and $42.8 \%$ can operate a bank account without their partner (Fig. 1, Additional file 3: Table S3).

\section{Association of CASR-SF items with Women's autonomy scale items}

The results of the CASR-SF showed $15.2 \%$ of abuse, divided into sexual (1.8\%), physical (1.8\%), verbal (73.2\%), physical/verbal (19.6\%), and physical/verbal/sexual (3.6\%).

Table 2 shows the association of all WAI aspects with the CASR-SF scale, dichotomized into abused $(\mathrm{N}=96$; $26 \%)$ versus not abused women $(\mathrm{N}=273 ; 74 \%)$.

Regarding the CASR-SF total score, the results showed that among women who do not operate a bank account, $24.3 \%$ were abused, while among those who have a joint account, $12.7 \%$ experienced abuse, and among women who operate their own account, $33.5 \%$ were abused.

As for the CASR-SF psychological sub-scale, it was found that among women who do not operate a bank account, $22.1 \%$ endured abuse, while among those who have a joint account, $12.7 \%$ were abused, and among those who operate their own account $31 \%$ were abused (Table 2).

\section{Bivariate analysis: correlates of the WAI}

Table 3 presents the bivariate analysis taking the WAI as a dependent variable. The results showed a significant association between high WAI scores and women and partners with high education levels and high monthly incomes. Additionally, lower WAI scores were significantly associated with higher stress, higher anxiety, higher sexual violence, and a higher total violence score.

\section{Multivariable analysis}

The first linear regression taking the Women's Autonomy Index as the dependent variable in the context of the woman's characteristics showed that university education level (beta $=1.263$ ), alcohol consumption (beta $=0.586)$, intermediate income level $($ beta $=0.702)$, high income (beta $=0.911)$, employment 
Table 1 Sociodemographic and other characteristics of the studied sample $(\mathrm{N}=369)$

\begin{tabular}{|c|c|c|}
\hline & Woman's response & $\begin{array}{l}\text { Partner characteristics } \\
\text { reported by woman }\end{array}$ \\
\hline & Frequency (\%) & Frequency (\%) \\
\hline \multicolumn{3}{|l|}{ Education level } \\
\hline Primary & $3(0.8 \%)$ & $18(4.9 \%)$ \\
\hline Complementary & $11(3.0 \%)$ & $34(9.2 \%)$ \\
\hline Secondary & $32(8.7 \%)$ & $64(17.3 \%)$ \\
\hline University & $323(87.5 \%)$ & $253(68.6 \%)$ \\
\hline \multicolumn{3}{|l|}{ Religion } \\
\hline Christian & $115(31.2 \%)$ & $115(31.2 \%)$ \\
\hline Muslim & $155(42.0 \%)$ & $159(43.1 \%)$ \\
\hline Druze & 81 (22.0\%) & 80 (21.7\%) \\
\hline Atheist & $2(0.5 \%)$ & $2(0.5 \%)$ \\
\hline Refused to answer & $16(4.3 \%)$ & $13(3.5 \%)$ \\
\hline \multicolumn{3}{|l|}{ Working status } \\
\hline Employed & $221(59.9 \%)$ & $334(90.5 \%)$ \\
\hline Unemployed & $148(40.1 \%)$ & 35 (9.5\%) \\
\hline \multicolumn{3}{|l|}{ Monthly income } \\
\hline No income & $102(27.6 \%)$ & $19(5.1 \%)$ \\
\hline Low & $94(25.5 \%)$ & $71(19.2 \%)$ \\
\hline Intermediate & $112(30.4 \%)$ & $168(45.5 \%)$ \\
\hline High & $61(16.5 \%)$ & $111(30.2 \%)$ \\
\hline \multicolumn{3}{|l|}{ Smoking status } \\
\hline Non smoker & $254(68.8 \%)$ & $170(46.1 \%)$ \\
\hline Smoker & $115(31.2 \%)$ & $199(53.9 \%)$ \\
\hline \multicolumn{3}{|l|}{ Alcohol consumption } \\
\hline Yes & 40 (10.8\%) & $148(40.1 \%)$ \\
\hline No & $329(89.2 \%)$ & $221(59.9 \%)$ \\
\hline \multicolumn{3}{|l|}{ Physical activity } \\
\hline Yes & $157(42.5 \%)$ & $128(34.7 \%)$ \\
\hline \multirow[t]{2}{*}{ No } & $212(57.5 \%)$ & $241(65.3 \%)$ \\
\hline & Mean \pm SD & Mean \pm SD \\
\hline Age in years & $32.5 \pm 6.4$ & $37.6 \pm 7.2$ \\
\hline Duration of confinement (days) & $71.0 \pm 42.8$ & \\
\hline Fear of poverty & $5.8 \pm 3.2$ & \\
\hline
\end{tabular}

(beta $=0.559)$, and older age (beta $=0.033$ ), were significantly associated with greater autonomy. Whereas, living in South Lebanon (beta $=-0.668$ ) and being Druze (beta $=-323$ ) were associated with lower woman autonomy (Table 4, Model 1).

The second linear regression taking the Women's Autonomy Index as the dependent variable in the context of the partner's characteristics showed that a high income (beta $=0.628$ ), university education level (beta $=0.420)$, alcohol consumption (beta $=0.661$ ), and older age (beta $=0.021$ ) were significantly associated with higher woman autonomy while being Druze (beta $=-0.401)$ was significantly associated with lower woman autonomy (Table 4, Model 2).

Figure 2 displays the association of psychological variables with WAI scores, adjusted for woman's age, woman's age at marriage, duration between first meeting and marriage, the region of living, work status, education level, religion, physical activity, income, alcohol consumption, partner's alcohol consumption, partner's religion, partner's work status, partner's income. Women with low autonomy had significantly higher LAS-10 and PSS-4 scores (Additional file 3: Table S4). 


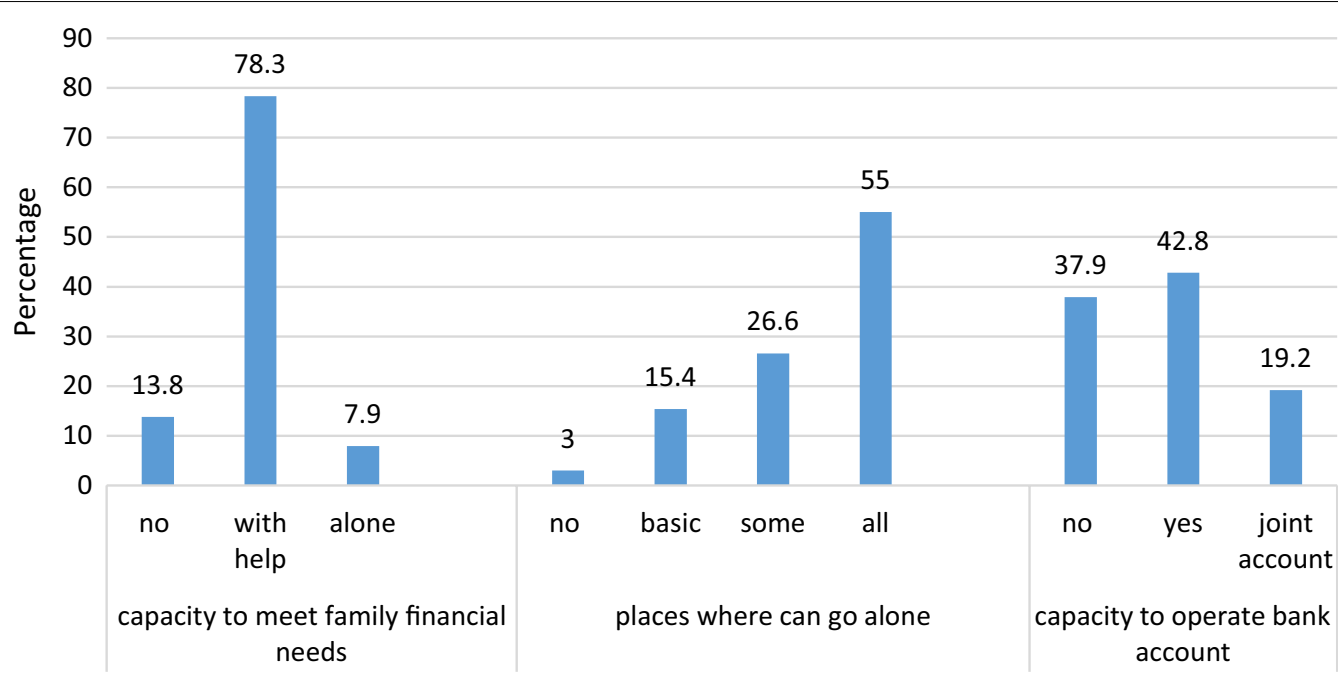

Fig. 1 Women's answers to the questions used to construct the Women's Autonomy Index

\section{Discussion}

To our knowledge, this study is the first in Lebanon related to women's autonomy, its associated factors, and mental health aspects. The vast majority (more than 90\%) of participants were not able to fulfill the economic needs of their family, while around half of them could not go to places they want, or operate a bank account without their partner, although our sample included highly educated women with easy access to the Internet (online survey). Nevertheless, compared to non-abused, abused women were more likely to have their own bank account, probably as a coping mechanism. A possible explanation of this result could be that most local and international organizations advocating against domestic violence encourage abused women to protect themselves financially, when possible, through several means, including opening and running a personal bank account, which is relatively easy in Lebanon, where the authorization of a tutor is not required $[28,29]$.

It is also noteworthy that the percentage of women with university education was higher than that of their partners, while employment and income were much higher among men. These results are in agreement with the Lebanese social-economic context [30]: despite women being more educated, the majority still work at the lower levels of the economic pyramid, even though $30-50 \%$ of the workforce consists of females, and the economic empowerment of woman plays a significant role in facilitating the achievement of a higher level of economic welfare $[15,31]$. Inspired by religious discourse, this legal structure classifies Lebanese women as second-class citizens, treating them as minors in decisions related to governing their own lives [32].
In this complex structure, our study also showed that personal and partner-related factors were associated with the autonomy of women, from the financial, operational, and social facets (the three questions of the index). Women's autonomy was positively associated with a university education, alcohol consumption, intermediate to high-income level vs. lower-income categories), employment, and age. Oppositely, some cultures seem to be associated with a lower autonomy of women, such as living in South Lebanon and being Druze. Our results are consistent with those of previous studies showing that, among Lebanese women, ambitions, values, and priorities related to education and economic independence differ according to religious and cultural differences $[8,31]$. The patriarchal character of the Lebanese society might be the primary reason for these differences [33]. As for age and education, our results are similar to those found in other developing countries, such as Ethiopia [1], India [6], Nepal [7], and Uganda [34].

Regarding the characteristics of partners, high income, university education, alcohol consumption, and older age are associated with the autonomy of women, while being Druze was inversely associated with it. Our results revealed that the characteristics of partners are as important as those of women. Thus, education, income, and cultural background of the partner are influential drivers of autonomy; our findings are consistent with those of studies in other developing countries, such as Uganda [34], Nepal [10], and Ethiopia [11].

Women's autonomy was significantly associated with lower perceived stress and lower anxiety, in agreement with previous findings. The evidence from a systematic review suggests that lower control or autonomy of women 
Table 2 Association of CASR-SF items with Women's autonomy scale items

\begin{tabular}{|c|c|c|c|c|c|c|}
\hline & \multicolumn{6}{|c|}{ Item 1: Capacity to meet family financial needs } \\
\hline & No & With help & Alone & \multicolumn{3}{|l|}{$p$ value } \\
\hline \multicolumn{7}{|c|}{ CASR-SF total } \\
\hline No abuse & $36(70.6 \%)$ & $215(74.4 \%)$ & $22(75.9 \%)$ & \multicolumn{2}{|l|}{0.825} & \\
\hline Abuse & $15(29.4 \%)$ & $74(25.6 \%)$ & $7(24.1 \%)$ & & & \\
\hline \multicolumn{7}{|c|}{ CASR-SF psychological } \\
\hline No abuse & $37(72.5 \%)$ & $221(76.5 \%)$ & $22(75.9 \%)$ & \multicolumn{2}{|l|}{0.833} & \\
\hline Abuse & $14(27.6 \%)$ & $68(23.5 \%)$ & $7(24.1 \%)$ & & & \\
\hline \multicolumn{7}{|c|}{ CASR-SF physical } \\
\hline No abuse & $47(92.3 \%)$ & $263(91 \%)$ & $28(96.6 \%)$ & \multicolumn{2}{|l|}{0.663} & \\
\hline Abuse & $4(7.8 \%)$ & $26(9 \%)$ & $1(3.4 \%)$ & & & \\
\hline \multicolumn{7}{|c|}{ CASR-SF sexual } \\
\hline No abuse & $47(92.2 \%)$ & $275(95.2 \%)$ & $29(100 \%)$ & \multicolumn{2}{|l|}{0.301} & \\
\hline \multirow[t]{3}{*}{ Abuse } & $4(7.8 \%)$ & $14(4.8 \%)$ & $0(0 \%)$ & & & \\
\hline & \multicolumn{6}{|c|}{ Item 2: Capacity to operate a bank account } \\
\hline & No & Joint account & Yes & \multicolumn{2}{|l|}{$p$ value } & \\
\hline \multicolumn{7}{|c|}{ CASR-SF total } \\
\hline No abuse & $106(75.7 \%)$ & $62(87.3 \%)$ & $105(66.5 \%)$ & 0.003 & & \\
\hline Abuse & $34(24.3 \%)$ & $9(12.7 \%)$ & $53(33.5 \%)$ & & & \\
\hline CASR-SF PSY & & & & & & \\
\hline No abuse & $109(77.9 \%)$ & $62(87.3 \%)$ & $109(69 \%)$ & 0.009 & & \\
\hline Abuse & $31(22.1 \%)$ & $9(12.7 \%)$ & $149(31 \%)$ & & & \\
\hline CASR-SFph & & & & & & \\
\hline No abuse & $129(92.1 \%)$ & $69(97.2 \%)$ & $140(88.6 \%)$ & 0.092 & & \\
\hline Abuse & $11(7.9 \%)$ & $2(2.8 \%)$ & $18(11.4 \%)$ & & & \\
\hline CASR-SF sex & & & & & & \\
\hline No abuse & $129(92.1 \%)$ & $69(97.2 \%)$ & $153(96.8 \%)$ & 0.135 & & \\
\hline Abuse & $11(7.9 \%)$ & $2(2.8 \%)$ & $5(3.2 \%)$ & & & \\
\hline & Item 3: Pla & she can go alon & & & & \\
\hline & No & Basic & Some & & All & $p$ value \\
\hline CASR-SF tot & & & & & & \\
\hline No abuse & 10 (90.9\%) & $43(75.4 \%)$ & $73(74.5 \%)$ & & 147 (72.4\%) & 0.596 \\
\hline Abuse & 1 (9.1\%) & $14(24.6 \%)$ & $25(25.5 \%)$ & & $56(27.6 \%)$ & \\
\hline CASR-SF pSY & & & & & & \\
\hline No abuse & 10 (90.9\%) & 43 (75.4\%) & $74(75.5 \%)$ & & 153 (75.4\%) & 0.723 \\
\hline Abuse & 1 (9.1\%) & $14(24.6 \%)$ & $24(24.5 \%)$ & & $50(24.6 \%)$ & \\
\hline CASR-SF ph & & & & & & \\
\hline No abuse & $11(100 \%)$ & 50 (87.7\%) & 92 (93.9\%) & & 185 (91.1\%) & 0.400 \\
\hline Abuse & $0(0 \%)$ & 7 (12.3\%) & $6(6.1 \%)$ & & 18 (8.9\%) & \\
\hline CASR-SF sex & & & & & & \\
\hline No abuse & $11(100 \%)$ & 52 (91.2\%) & 97 (99\%) & & $191(94.1 \%)$ & 0.102 \\
\hline Abuse & $0(0 \%)$ & 5 (8.8\%) & $1(1 \%)$ & & 12 (5.9\%) & \\
\hline
\end{tabular}

Note: Values marked in Bold are significant

(e.g., lack of freedom of movement outside the home) was associated with poorer mental health for women after adjusting for their socioeconomic circumstances [35].
High agency in household decision-making has direct implications for women's control over household material resources, such as income and assets, which may give 
Table 3 Bivariate analysis taking the Women's Autonomy Index as the dependent variable

\begin{tabular}{|c|c|c|c|c|}
\hline & \multicolumn{4}{|c|}{ Women's Autonomy Index } \\
\hline & \multicolumn{2}{|c|}{ Woman's characteristics } & \multicolumn{2}{|c|}{ Partner's characteristics } \\
\hline & $\mathbf{r}$ & $p$ value & $\mathbf{r}$ & $p$ value \\
\hline Age & 0.248 & $<0.001$ & 0.156 & 0.003 \\
\hline Age at marriage & 0.290 & $<0.001$ & 0.019 & 0.721 \\
\hline Age at birth of first child & 0.272 & $<0.001$ & 0.022 & 0.700 \\
\hline $\begin{array}{l}\text { Duration between the first meeting and } \\
\text { marriage }\end{array}$ & 0.182 & $<0.001$ & & \\
\hline Perceived stress (PSS-4) & -0.117 & 0.024 & & \\
\hline Anxiety scale (LAS-10) & -0.204 & $<0.001$ & & \\
\hline Depression scale (PHQ-9) & -0.099 & 0.058 & & \\
\hline CASR-SF total & -0.106 & 0.041 & & \\
\hline CASR-SF psychological & -0.097 & 0.062 & & \\
\hline CASR-SF physical & -0.031 & 0.551 & & \\
\hline \multirow[t]{2}{*}{ CASR-SF sexual } & -0.131 & 0.012 & & \\
\hline & Mean (SD) & $p$ value & Mean (SD) & $p$ value \\
\hline \multicolumn{5}{|l|}{ Education level } \\
\hline School education & $2.65(1.36)$ & $<0.001$ & $3.85(1.67)$ & $<0.001$ \\
\hline University education & $4.56(1.43)$ & & $4.54(1.45)$ & \\
\hline \multicolumn{5}{|l|}{ Religion* } \\
\hline Christian & $4.80(1.29)$ & 0.001 & $4.80(1.29)$ & $<0.001$ \\
\hline Muslim & $4.11(1.69)$ & & $4.10(1.68)$ & \\
\hline Druze & $4.01(1.54)$ & & $4.00(1.54)$ & \\
\hline Other & $4.55(1.38)$ & & $4.73(1.33)$ & \\
\hline \multicolumn{5}{|l|}{ Work status } \\
\hline Unemployed & $3.71(1.60)$ & $<0.001$ & $4.17(1.74)$ & 0.540 \\
\hline Employed & $4.73(1.38)$ & & $4.34(1.53)$ & \\
\hline \multicolumn{5}{|l|}{ Monthly income* } \\
\hline No income & $3.33(1.41)$ & $<0.001$ & $3.79(1.93)$ & $<0.001$ \\
\hline Low income & $4.08(1.40)$ & & $3.75(1.69)$ & \\
\hline Intermediate income & $4.98(1.24)$ & & $4.23(1.46)$ & \\
\hline High income & $5.15(1.54)$ & & $4.94(1.34)$ & \\
\hline \multicolumn{5}{|l|}{ Alcohol consumption } \\
\hline Yes & $5.62(0.80)$ & $<0.001$ & $4.81(1.30)$ & $<0.001$ \\
\hline No & $4.16(1.55)$ & & $4.00(1.62)$ & \\
\hline \multicolumn{5}{|l|}{ Type of smoking* } \\
\hline Cigarette & $4.72(1.37)$ & 0.025 & $4.20(1.49)$ & 0.194 \\
\hline Waterpipe & $4.06(1.62)$ & & $4.44(1.44)$ & \\
\hline Cigarette and waterpipe & $5.43(1.27)$ & & $4.30(2.00)$ & \\
\hline Other & $4.28(1.59)$ & & $5.18(0.98)$ & \\
\hline \multicolumn{5}{|l|}{ Physical activity } \\
\hline No & $4.19(1.62)$ & 0.059 & $4.35(1.56)$ & 0.642 \\
\hline Yes & $4.50(1.45)$ & & $4.27(1.54)$ & \\
\hline \multicolumn{5}{|l|}{ Living region* } \\
\hline Mount Lebanon & $4.38(1.50)$ & 0.023 & & \\
\hline Beirut & $4.64(1.58)$ & & & \\
\hline North & $4.32(1.46)$ & & & \\
\hline South & $3.38(1.74)$ & & & \\
\hline Beqaa & $4.16(1.80)$ & & & \\
\hline
\end{tabular}


Table 3 (continued)

\begin{tabular}{llcc}
\hline & Mean (SD) & $\boldsymbol{p}$ value & Mean (SD) \\
\hline Living place & & $\mathbf{p}$ value \\
Urban & $4.45(1.54)$ & & \\
Rural & $4.06(1.57)$ & & \\
\hline
\end{tabular}

Note: Values marked in Bold are significant

*Bonferroni Post-hoc analysis: religion of women: Christian versus Muslim $p=0.002$; Christian versus Druze $p=0.003$, Christian versus other $p=1.000$, Muslim versus Druze $p=1.000$, Muslim versus other $p=1.000$, Druze versus other $p=1.000$

Religion of partners: Christian versus Muslim $p=0.001$; Christian versus Druze $p=0.002$, Christian versus other $p=1.000$, Muslim versus Druze $p=1.000$, Muslim versus other $p=0.750$, Druze versus other $p=0.528$

Woman's monthly income: no income versus low-income $p=0.001$, no versus intermediate income $p<0.001$, no versus high-income $p<0.001$, low versus intermediate income $p<0.001$, low versus high-income $p<0.001$, intermediate versus high-income $p=1.000$

Partner's monthly income: no income versus low-income $p=1.000$, no versus intermediate income $p=1.000$, no versus high-income $p=0.013$, low versus intermediate income $p=0.146$, low versus high-income $p<0.001$, intermediate versus high-income $p=0.001$

Woman's type of smoking: cigarette versus waterpipe $p=0.190$, cigarette versus waterpipe/cigarette $p=0.869$, waterpipe versus waterpipe/cigarette $p=0.081$ Living region: Mount Lebanon versus Beirut $p=1.000$, Mount Lebanon versus North $p=1.000$, Mount Lebanon versus South $p=0.026$, Mount Lebanon versus Beqaa $p=0.026$, Beirut versus North $p=1.000$, Beirut versus South $p=0.012$, Beirut versus Beqaa $p=1.000$, North versus South $p=0.164$, North versus Beqaa $p=1.000$, South versus Beqaa $p=0.991$

Table 4 Multivariable analysis

\begin{tabular}{|c|c|c|c|c|}
\hline Factor & Unstandardized beta & Standardized beta & $95 \% \mathrm{Cl}$ & $p$ value \\
\hline \multicolumn{5}{|c|}{ Linear regression 1 taking the Women's Autonomy Index as dependent variable in the context of the woman's characteristics } \\
\hline University education versus school education ${ }^{\mathrm{a}}$ & 1.263 & 0.268 & $0.847 ; 1.679$ & $<0.001$ \\
\hline Alcohol consumption (Yes vs. $\mathrm{No}^{\mathrm{a}}$ ) & 0.586 & 0.117 & $0.119 ; 1.053$ & 0.014 \\
\hline Woman intermediate income versus no income ${ }^{a}$ & 0.702 & 0.207 & $0.381 ; 1.024$ & $<0.001$ \\
\hline Woman high income versus no income $e^{\mathrm{a}}$ & 0.911 & 0.218 & $0.504 ; 1.318$ & $<0.001$ \\
\hline Woman employed versus unemployed ${ }^{a}$ & 0.559 & 0.176 & $0.263 ; 0.855$ & $<0.001$ \\
\hline Woman age (years) & 0.033 & 0.133 & $0.011 ; 0.054$ & 0.003 \\
\hline Living in South Lebanon versus Mount Lebanon ${ }^{\mathrm{a}}$ & -0.668 & -0.106 & $-1.205 ;-0.132$ & 0.015 \\
\hline Woman Druze versus Christian ${ }^{\mathrm{a}}$ & -0.323 & -0.086 & $-0.638 ;-0.008$ & 0.044 \\
\hline \multicolumn{5}{|c|}{ Linear regression 2 taking the Women's Autonomy Index as dependent variable in the context of the partner's characteristics } \\
\hline High monthly income versus no income $e^{b}$ & 0.628 & 0.185 & $0.285 ; 0.972$ & $<0.001$ \\
\hline Alcohol consumption (yes vs. no ${ }^{b}$ ) & 0.661 & 0.208 & $0.347 ; 0.975$ & $<0.001$ \\
\hline University education versus school education ${ }^{b}$ & 0.420 & 01.125 & $0.082 ; 0.758$ & 0.015 \\
\hline Woman Druze versus Christian ${ }^{b}$ & -0.401 & -0.106 & $-0.761 ;-0.040$ & 0.030 \\
\hline Age & 0.021 & 0.098 & $0.001 ; 0.042$ & 0.050 \\
\hline
\end{tabular}

${ }^{a}$ Variables entered: region of living, work status, education level, religion, physical activity, income, age, alcohol consumption

${ }^{b}$ Variables entered: partner's alcohol consumption, partner's education level, partner's religion, partner's work status, partner's income

Variables that were not entered in the model ( $p$ values not significant): partner's work status, partner's type of smoking, partner's physical activity, partner's age at marriage, partner's age at birth of first child

women additional resources to cope with adverse conditions and life stressors [36]. Some autonomy components may be associated with experiencing anxiety in different situations (e.g., related to others' distress or presenting one's personal views) [37]; also, low autonomy in decision-making is related to higher levels of common mental disorders, including anxiety and depression [38]. In Egypt, anxiety was related to premarital variables in particular, such as education and socioeconomic level, which in turn are related to the autonomy of women [39].
The association of autonomy with depression and abuse yielded positive but non-significant results. Social and economic empowerment were similarly correlated to depressive symptoms in Afghanistan [40]. A study comparing Turkish to German women found that autonomy was associated with higher levels of mental health in both Turkish and German women (lower depression) [41]. Thus, empowerment may protect women against intimate partner violence overall, but this relationship can be reversed at the micro-level [42]. 


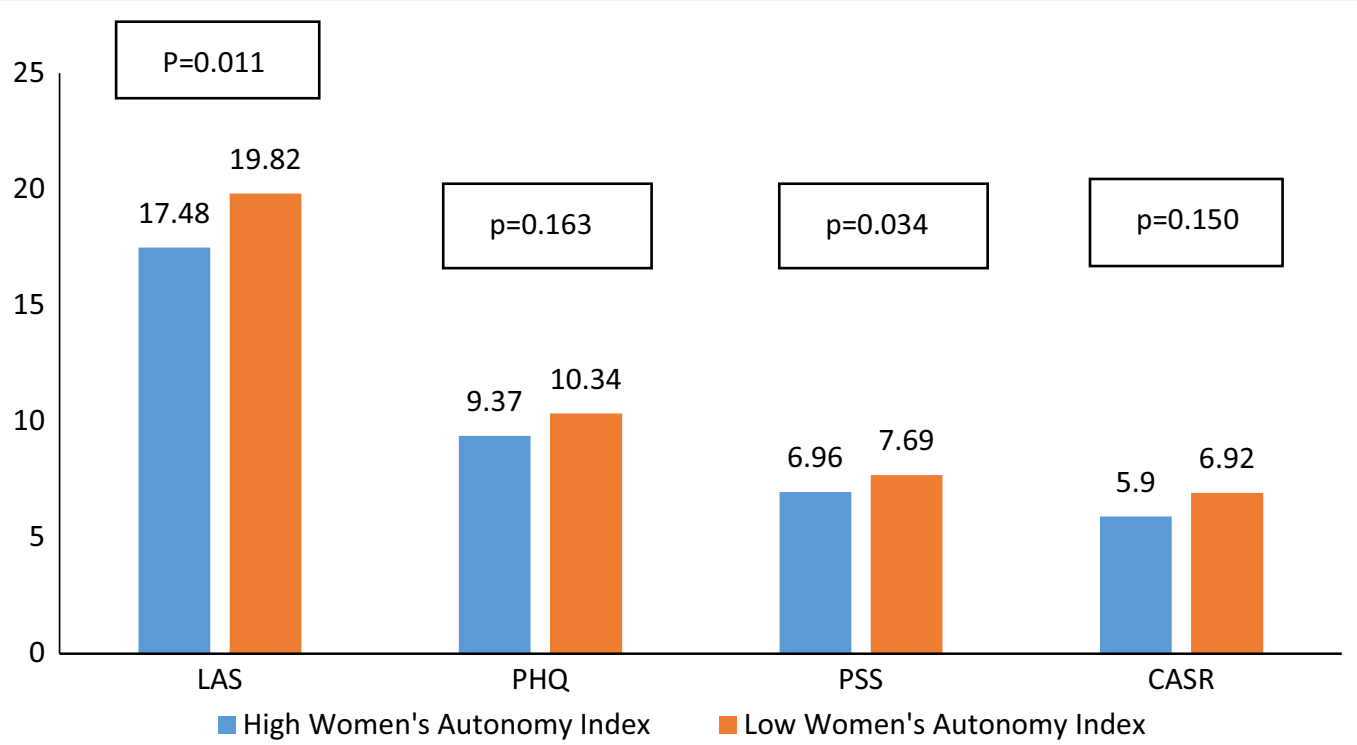

Fig. 2 Adjusted means of psychological variables according to the Women's Autonomy Index. LAS Lebanese Anxiety Scale, PHQ Patient Health Questionnaire for depression measurement, CASR Composite Abuse Scale Revised, PSS-4 Perceived Stress Scale

\section{Study limitations}

This study has several limitations. Its cross-sectional design cannot show causality but only generates hypotheses. A selection bias is suspected, given that only educated women with higher socioeconomic status and internet access could answer the online survey, which leads to the underestimation of our results. Indeed, data show that $57 \%$ of Lebanese women have university education compared to $87.5 \%$ in our sample [30]. Further underestimation may be linked to non-differential information bias due to self-declared answers with possibilities of recall or social desirability biases. Finally, although a multivariate analysis was conducted, the possibility of residual confounding cannot be ruled out. Further prospective studies that take into account these pitfalls are necessary to confirm our results.

\section{Conclusion}

This study showed that, in Lebanon, the autonomy and empowerment of women depend on several personal and partner-related characteristics (education, socioeconomic status, age), in addition to the cultural (geographic and religious) environment. Furthermore, low autonomy is associated with higher perceived stress and anxiety and probable depression and domestic abuse.

\section{Abbreviations}

WAI: Women's Autonomy Index; USD: United States dollar; CASR-SF: The Composite Abuse Scale Revised-Short Form; PSS-4: Perceived stress scale short version; LAS-10: Lebanese Anxiety Scale; PHQ-9: Patient Health Questionnaire; SPSS: Statistical Package for Social Sciences; Cl: Confidence interval.

\section{Supplementary Information}

The online version contains supplementary material available at https://doi. org/10.1186/s12905-021-01501-3.

Additional file 1. STROBE Statement checklist.

Additional file 2. Woman Autonomy Index questionnaire.

Additional file 3. Table 1: Factor structured of the Women autonomy index. Table 2: Factor structured of the Composite Abuse Scale (Revised) - Short Form (CASR-SF). Table 3: Description of the women autonomy index items. Table 4: Association between the women autonomy index and psychological factors.

\section{Acknowledgements}

The authors would like to thank all those who participated in this study, and Mrs. Mireille Awad Zeinoun for the research idea and for helping in data collection. Also, special thanks go to the Order of Midwives in Lebanon who helped in the data collection by filling up and spreading the web-based online survey.

\section{Authors' contributions}

SBM designed the study; PS, CH, DM, SBM drafted the manuscript; $\mathrm{CH}, \mathrm{SBM}$, and PS carried out the analysis and interpreted the results; PS, HS, DK, NL, JA assisted in drafting and reviewing the manuscript; $\mathrm{CH}, \mathrm{DM}, \mathrm{DK}, \mathrm{NL}, \mathrm{JA}$, and SBM were responsible for data collection; $\mathrm{HS}$ edited the paper for English language, PS supervised the course of the article. All authors reviewed and approved the final version of the manuscript.

\section{Funding}

None.

Availability of data and materials

Data can be made available under reasonable request form the corresponding author. 


\section{Declarations}

\section{Ethics approval and consent to participate}

The Psychiatric Hospital of the Cross ethics committee approved the study protocol (HPC-018-2020). Online Informed consent was obtained from each participant involved in this study on the first page of the questionnaire. All procedures were performed in accordance with relevant guidelines. This study is part of a larger research project related to several aspects of women's health during the COVID-19 pandemic, including pregnancy, violence, and mental health.

\section{Consent for publication}

Not applicable.

\section{Competing interests}

The authors declare that they have no competing interests.

\section{Author details}

${ }^{1}$ INSPECT-LB (Institut National de Santé Publique, d'Épidémiologie Clinique et de Toxicologie-Liban), Beirut, Lebanon. ${ }^{2}$ School of Pharmacy, Lebanese International University, Beirut, Lebanon. ${ }^{3}$ Faculty of Public Health, Lebanese University, Fanar, Lebanon. ${ }^{4}$ Faculty of Pharmacy, Lebanese University, Beirut, Lebanon. ${ }^{5} \mathrm{Clinical}$ and Epidemiological Research Laboratory, Faculty of Pharmacy, Lebanese University, Hadat, Lebanon. ${ }^{6}$ Research Department, Psychiatric Hospital of the Cross, P.O. Box 60096, JalEddib, Lebanon. ${ }^{7}$ INSERM, Univ. Limoges, CH Esquirol, IRD, U1094 Tropical Neuroepidemiology, Institute of Epidemiology and Tropical Neurology, GEIST, Limoges, France. ${ }^{8}$ University of Nicosia Medical School, Nicosia, Cyprus. ${ }^{9}$ Faculté de santé, Université Sainte Famille, Batroun, Lebanon.

Received: 31 October 2020 Accepted: 5 October 2021

Published online: 20 October 2021

\section{References}

1. Nigatu D, Gebremariam A, Abera M, Setegn T, Deribe K. Factors associated with women's autonomy regarding maternal and child health care utilization in Bale Zone: a community based cross-sectional study. BMC Womens Health. 2014;14(1):79.

2. Brunson EK, Shell-Duncan B, Steele M. Women's autonomy and its relationship to children's nutrition among the Rendille of northern Kenya. Am J Hum Biol. 2009;21(1):55-64.

3. Kishor S, Subaiya L. Understanding women's empowerment: a comparative analysis of Demographic and Health Surveys (DHS) data. Macro International; 2008

4. Sen G, Batliwala S. Empowering women for reproductive rights. 2000.

5. Tiwari M, Kumar K. Women's autonomy and utilization of maternal and child health care services in India. Population Association of America. Retrieved from https://paa2010.princeton.edu/papers/101177.

6. Singh K, Singh K, Singh B, Pathak A. Impact of education and autonomy on fertility of women in Eastern Uttar Pradesh. Demogr India. 2002;31(2):223-34.

7. Acharya DR, Bell JS, Simkhada P, Van Teijlingen ER, Regmi PR. Women's autonomy in household decision-making: a demographic study in Nepal. Reprod Health. 2010;7(1):15.

8. Kritz MM, Makinwa-Adebusoye P, editors. Determinants of women's decision-making authority in Nigeria: the ethnic dimension. Sociological forum. Springer; 1999

9. Feyisetan BJ. Spousal communication and contraceptive use among the Yoruba of Nigeria. Popul Res Policy Rev. 2000;19(1):29-45.

10. Furuta M, Salway S. Women's position within the household as a determinant of maternal health care use in Nepal. Int Fam Plan Perspect. 2006;32:17-27.

11. Tadele A, Tesfay A, Kebede A. Factors influencing decision-making power regarding reproductive health and rights among married women in Mettu rural district, south-west, Ethiopia. Reprod Health. 2019;16(1):155.

12. Zhang L, Wang K, Zhu C, Yu F, Chen X. Trait anxiety has effect on decision making under ambiguity but not decision making under risk. PLoS ONE. 2015:10(5):e0127189.
13. Wemm SE, Wulfert E. Effects of acute stress on decision making. Appl Psychophysiol Biofeedback. 2017;42(1):1-12.

14. Leykin Y, Roberts CS, DeRubeis RJ. Decision-making and depressive symptomatology. Cogn Ther Res. 2011;35(4):333-41.

15. Avis W. Gender equality and women's empowerment in Lebanon. 2017.

16. Melki I, Beydoun H, Khogali M, Tamim H, Yunis K. Household crowding index: a correlate of socioeconomic status and inter-pregnancy spacing in an urban setting. J Epidemiol Community Health. 2004;58(6):476-80.

17. Diop-Sidibé N, Campbell JC, Becker S. Domestic violence against women in Egypt — wife beating and health outcomes. Soc Sci Med. 2006;62(5):1260-77.

18. Ford-Gilboe M, Wathen C, Varcoe C, MacMillan H, Scott-Storey K, Mantler $\mathrm{T}$, et al. Development of a brief measure of intimate partner violence experiences: the composite abuse scale (Revised)-short form (CASR-SF) Creative Commons License; 2016

19. Cohen S, Kamarck T, Mermelstein R. A global measure of perceived stress. J Health Soc Behav. 1983;24:385-96.

20. Lee $\mathrm{E}-\mathrm{H}$. Review of the psychometric evidence of the perceived stress scale. Asian Nurs Res. 2012;6(4):121-7.

21. Chaaya M, Osman H, Naassan G, Mahfoud Z. Validation of the Arabic version of the Cohen Perceived Stress Scale (PSS-10) among pregnant and postpartum women. BMC Psychiatry. 2010;10(1):111.

22. Almadi T, Cathers I, Mansour AMH, Chow CM. An Arabic version of the Perceived Stress Scale: translation and validation study. Int J Nurs Stud. 2012:49(1):84-9.

23. Hallit S, Obeid S, Haddad C, Hallit R, Akel M, Haddad G, et al. Construction of the Lebanese Anxiety Scale (LAS-10): a new scale to assess anxiety in adult patients. Int J Psychiatry Clin Pract. 2020;24:1-8.

24. Kroenke K, Spitzer RL. The PHQ-9: a new depression diagnostic and severity measure. Psychiatr Ann. 2002;32(9):509-15.

25. Spitzer RL, Kroenke K, Williams JB, Group PHQPCS. Validation and utility of a self-report version of PRIME-MD: the PHQ primary care study. JAMA 1999;282(18):1737-44.

26. SprzeR R, Williams J, Kroene K, Hornyak R, Mcmurrax J. Validity and utility of the Patient Health Questionnaire in assessment of 3000 obstetricgynecologic patients: the PRIME-MD Patient Health Questionnaire Obstetrics-Gynecology Study. Am J Obstetr Gynecol. 2000;183:759-69.

27. Sawaya H, Atoui M, Hamadeh A, Zeinoun P, Nahas Z. Adaptation and initial validation of the Patient Health Questionnaire-9 (PHQ-9) and the Generalized Anxiety Disorder-7 Questionnaire (GAD-7) in an Arabic speaking Lebanese psychiatric outpatient sample. Psychiatry Res. 2016;239:245-52.

28. KAFA. Enough violence and exploitation. https://kafa.org.lb/en. Last accessed 21 Jan 2021

29. UNDP Lebanon. Empowering Lebanese women to achieve financial independence. 2017. https://www.lb.undp.org/content/lebanon/en/home/ presscenter/articles/2017/08/24/empowering-lebanese-women-to-achie ve-financial-independence.html\#: :text=The\%20program\%20targets\% 20five\%20governorates,assistance\%20in\%20their\%20current\%20professi on. Last accessed 21 Jan 2021.

30. Knowledge ealfdKD. Gender equality and women's empowerment in Lebanon. 2017. https://reliefweb.int/sites/reliefweb.int/files/resources/ 175-Gender-Equality-and-Womens-Empowerment-in-Lebanon.pdf. Last accessed 21 Jan 2021

31. Bassam H, Hussin H, Fadi E-H, Jessica LP, Rebecca B. Economic empowerment of women in Lebanon. World J Soc Sci Res. 2015;2(2):251.

32. Salameh R. Gender politics in Lebanon and the limits of legal reformism (En-Ar). 2014.

33. Jejeebhoy SJ, Sathar ZA. Women's autonomy in India and Pakistan: the influence of religion and region. Popul Dev Rev. 2001;27(4):687-712.

34. Sell M, Minot N, editors. What factors explain women's empowerment? Decision-making among small-scale farmers in Uganda. Women's Studies International Forum. Elsevier; 2018.

35. Pennington A, Orton L, Nayak S, Ring A, Petticrew M, Sowden A, et al. The health impacts of women's low control in their living environment: a theory-based systematic review of observational studies in societies with profound gender discrimination. Health Place. 2018:51:1-10.

36. Richardson RA, Harper S, Bates LM, Nandi A. The effect of agency on women's mental distress: a prospective cohort study from rural Rajasthan India. Soc Sci Med. 2019;233:47-56. 
37. Kunst L, Maas J, Van Assen M, Van der Heijden W, Bekker M. Autonomy deficits as vulnerability for anxiety: evidence from two laboratory-based studies. Anxiety Stress Coping. 2019;32(3):244-58.

38. Patel V, Kirkwood BR, Pednekar S, Pereira B, Barros P, Fernandes J, et al. Gender disadvantage and reproductive health risk factors for common mental disorders in women: a community survey in India. Arch Gen Psychiatry. 2006;63(4):404-13

39. Yount KM, Dijkerman S, Zureick-Brown S, VanderEnde KE. Women's empowerment and generalized anxiety in Minya, Egypt. Soc Sci Med. 2014;106:185-93.

40. Gibbs A, Corboz J, Chirwa E, Mann C, Karim F, Shafiq M, et al. The impacts of combined social and economic empowerment training on intimate partner violence, depression, gender norms and livelihoods among women: an individually randomised controlled trial and qualitative study in Afghanistan. BMJ Glob Health. 2020;5(3):e001946.
41. Balkir N, Arens EA, Barnow S. Exploring the relevance of autonomy and relatedness for mental health in healthy and depressed women from two different cultures: when does culture matter? Int J Soc Psychiatry. 2013;59(5):482-92.

42. Schuler SR, Lenzi R, Badal SH, Bates LM. Women's empowerment as a protective factor against intimate partner violence in Bangladesh: a qualitative exploration of the process and limitations of its influence. Violence Against Women. 2017;23(9):1100-21.

\section{Publisher's Note}

Springer Nature remains neutral with regard to jurisdictional claims in published maps and institutional affiliations.
Ready to submit your research? Choose BMC and benefit from:

- fast, convenient online submission

- thorough peer review by experienced researchers in your field

- rapid publication on acceptance

- support for research data, including large and complex data types

- gold Open Access which fosters wider collaboration and increased citations

- maximum visibility for your research: over 100M website views per year

At BMC, research is always in progress.

Learn more biomedcentral.com/submissions 